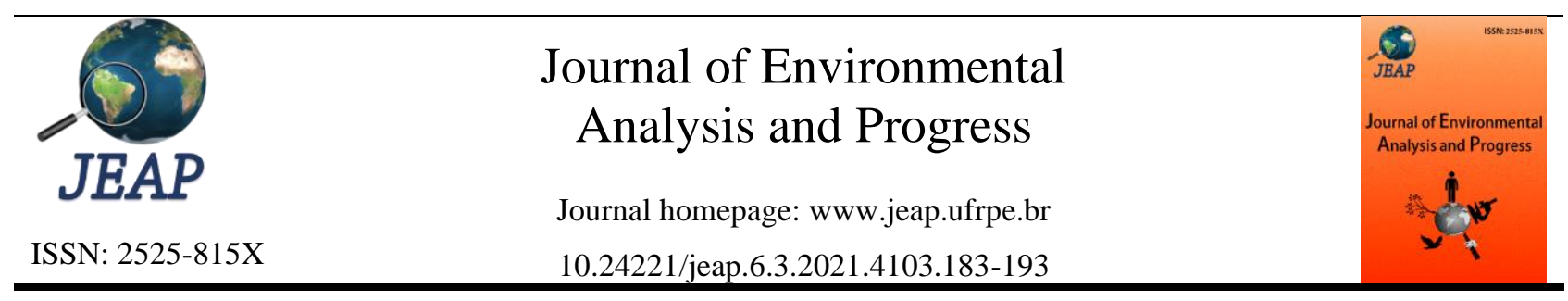

\title{
Hybrid computational model to assist in the location of victims buried in the tragedy of Brumadinho
}

Rafael Fernandes Pinheiro ${ }^{\mathrm{a}^{*}}$, Harold Ivan Angulo Bustos ${ }^{\mathrm{b} *}$, Bruno Bestle Turrin ${ }^{\mathrm{a}}$, Francisco Marcos da Costa Monteiro ${ }^{\mathrm{b}}$, Diego Colón ${ }^{\mathrm{a}}$, Mirelly Ferreira Silveira ${ }^{\mathrm{c}}$, Dário José Aloise ${ }^{\mathrm{b}}$, Alysson Mendes de Oliveira ${ }^{b}$

${ }^{\text {a }}$ Universidade de São Paulo-USP, Laboratório de Automação e Controle, Departamento de Telecomunicações e Controle. Av. Prof. Luciano Gualberto, Travessa 03, No. 158, São Paulo, SP, Brazil. CEP: 05508-900. E-mail: rafael.pinheiro@usp.br*, bbturrin@usp.br, diego@lac.usp.br.

${ }^{\mathrm{b}}$ Universidade Estadual do Rio Grande do Norte-UERN, Departmento de Informática. BR 110, Km 46, Rua Prof. Antonio Campos, S/N, Bairro Costa e Silva, Mossoró, Rio Grande do Norte, Brazil. E-mail: haroldivanangulobustos@gmail.com*, $\quad$ franciscomarcos1616@gmail.com, _ darioaloise@ uern.br, alyssonoliveira@uern.br.

c Mayday Pesquisas e Tecnologia Brasil Ltda. Rua Araçoiaba da Serra, No. 58, São Paulo, SP, Brasil. E-mail: mirellyferreirasilveira@gmail.com.

A R T I C L E I N F O
Received 19 Jan 2021

Accepted 26 Aug 2021

Published 06 Sep 2021

\begin{abstract}
A B S T R A C T
The rupture of dams in Brazil has caused great concern due to the environmental disaster and the loss of lives. The use of algorithms and computational models to assist search teams in locating victims when buried by tailings is essential but scarce. Those that exist are mainly slow, as they involve high computational costs. In this sense, in the context of the Brumadinho tragedy in 2019, this study aimed to develop a hybrid computational model to assist the search teams in locating victims buried by the tailings. The methodology for designing this model was based on regression techniques, machine learning, and physicomathematical algorithms. Firstly, the study resulted in a physicomathematical model based on integral and vector calculus and concepts of fluid mechanics, which provided results to assist in locating bodies buried by the tailings. More recently, based on data provided by the physicomathematical algorithm, two hybrid models have been developed. One uses statistical regression, and the other uses support vector regression, a type of machine learning. It is expected that a more accurate model can be used in other possible situations of disruption in future studies. Also, it is possible to apply the model developed in situations involving computational fluid dynamics in general.
\end{abstract}

Keywords: Computational modeling, dam-break, artificial intelligence, physicomathematical model.

\section{Introduction}

The disruption of a dam with approximately 12 million cubic meters of ores (Weter et al., 2019) was a tragedy that struck the city of Brumadinho, Minas Gerais, Brazil, in January of 2019, leaving around 300 fatal victims.

In the face of this horrible disaster, thousands of people mobilized themselves to offer help, including the military forces, firefighters, medical doctors, and professionals from many different areas. In view of locating buried victims' arduous work, scientists from all over Brazil have made themselves available to assist in what was possible, offering their expertise to help those affected by the tragedy. Those scientists became known as Group Science for Brumadinho.

Due to the difficulty of the land rescue teams to locate the buried victims in Brumadinho, the members of the group science for Brumadinho began developing computational models. The purpose of these models is to predict possible victims' locations, providing latitude and longitude estimates.

The increase in accidents involving dams has pushed studies that seek to simulate the dams' rupture and the flow of the tailings. It is considered a difficult task and problematic in fluid mechanics due to several factors: the computational cost for 
CFD simulations (Vacondio et al., 2014). Some studies use the classic Navier-Stokes equation to simulate the reject flow coming from a dam disruption, as we can see in the following paper Luo et al. (2017). Arising from the Navier-Stokes equations, Zhou et al. (2004) use a model based on the shallow water equations with appropriate source terms. Furthermore, a model based on the shallow water equations and the mass advectiondiffusion equation made in Zhang et al. (2018) can also be applied in dam-break.

However, some studies seek alternatives for this type of modeling, as seen in Daneshvar \& Zsaki (2018). Considering the case of Brumadinho, there is also the saddest difficulty: the need to estimate the final position of victims affected by the reject who got buried. The development of algorithms in this area becomes even more complex.

Recently, many studies using Support Vector Regression (SVR) for environmental predictions have emerged, for example, wind speed prediction (Santamaria et al., 2016), predict evaporation (Moazenzadeh et al., 2018; Qasem et al., 2019), air pollutant concentration (Li et al., 2019), and predicting the daily levels of groundwater (Guzman et al., 2019). The SVR has also been used in dams, as in Rehamnia et al. (2020) and Tabari \& Sanayei (2019). More specifically, for the dam rupture flow problem in Seyedashraf et al. (2018), the formation and propagation of shock and rarefaction waves are modeled using artificial neural networks of the type MLP and SVR via radial bases function kernel (RBF). Still, in Seyedashraf et al. (2018), unlike the literature, and like ours, there is no resolution of PDEs (Navier-Stokes equations) or any numerical discretization in space or time.

This study highlights the following contributions: a Physicomathematical 2D Model; a Physicomathematical Model with Interpolation; and a Physicomathematical Model with Support Vector Regression (SVR).

The Physicomathematical 2D Model is a model based on integral and vector calculus and fluid mechanics concepts. This model aims to simulate the reject flow and predict possible locations and trajectories of buried victims. This algorithm was the first to provide some results to help search teams (Piovezan, 2019; Gomes, 2020) at the time of the tragedy.

Concerning the Physicomathematical Model with Interpolation, after the tragedy period, to improve the model, this first hybrid model was developed. Using interpolation techniques via linear interpolation and cubic splines, the hybrid model was defined from the data provided by the physicomathematical model. Hybrid models that use these techniques are common, for example, Marcolino et al. (2018). However, the use of models for the purpose presented here is not usually found in the literature.

Based on Boser, Guyon \& Vapnik (Boser et al., 1992), the Physicomathematical Model with SVR uses kernel models and the data provided by the physicomathematical model.

\section{Material and Methods}

Due to the impossibility of obtaining information on the characteristics of the tailings with the company responsible for the dam, the thesis Alvarado (2006) was used. For the adjustments and validation of the algorithm, the General Procuratorate Office of the State of Minas Gerais (GPOSMG) provided information on the initial and final positions of victims that were located.

The methods used for the computational model design were based primarily on creating a physicomathematical model, using techniques of integral and vector calculus and concepts of fluid mechanics. Then, regression and machine learning techniques were used to create the hybrid model using data provided by the physicomathematical model. The software Matlab ${ }^{\circledR}$ was used for the development of the computational codes and simulations.

\section{Results and Discussion}

\section{Physicomathematical 2D model}

The physicomathematical model aims to provide estimates of latitude and longitude of possible buried victims. The model implemented via Matlab® uses differential and integral calculus, vector calculus, and fluid mechanics concepts.

The model's idea consists of determining the drag force exerted by the reject on affected victims. Obtaining the drag force is possible to determine the acceleration, velocity, and trajectory of the victim. It was necessary to obtain information about the reject's composition, such as density, viscosity, and velocity. The thesis Alvarado (2006) provided parameters of velocity and density of the tailings. GPOSMG provided information for validation, as explained in the previous section.

\section{$i$. The construction of the vector field}

Firstly, based on the literature's velocity (Alvarado, 2006), an artificial vector field of the reject's velocity was constructed along the route. Figure 1 shows the region of the town of Brumadinho affected by the reject. For the construction of the vector field, initially, the region 
was subdivided into 1024 sub-regions (see Figure 2), for this was necessary knowledge in treatment and manipulation of extensive data. Using vector calculation, the artificial field of the velocity of the reject was built using the quiver Matlab® function (Figure 3).

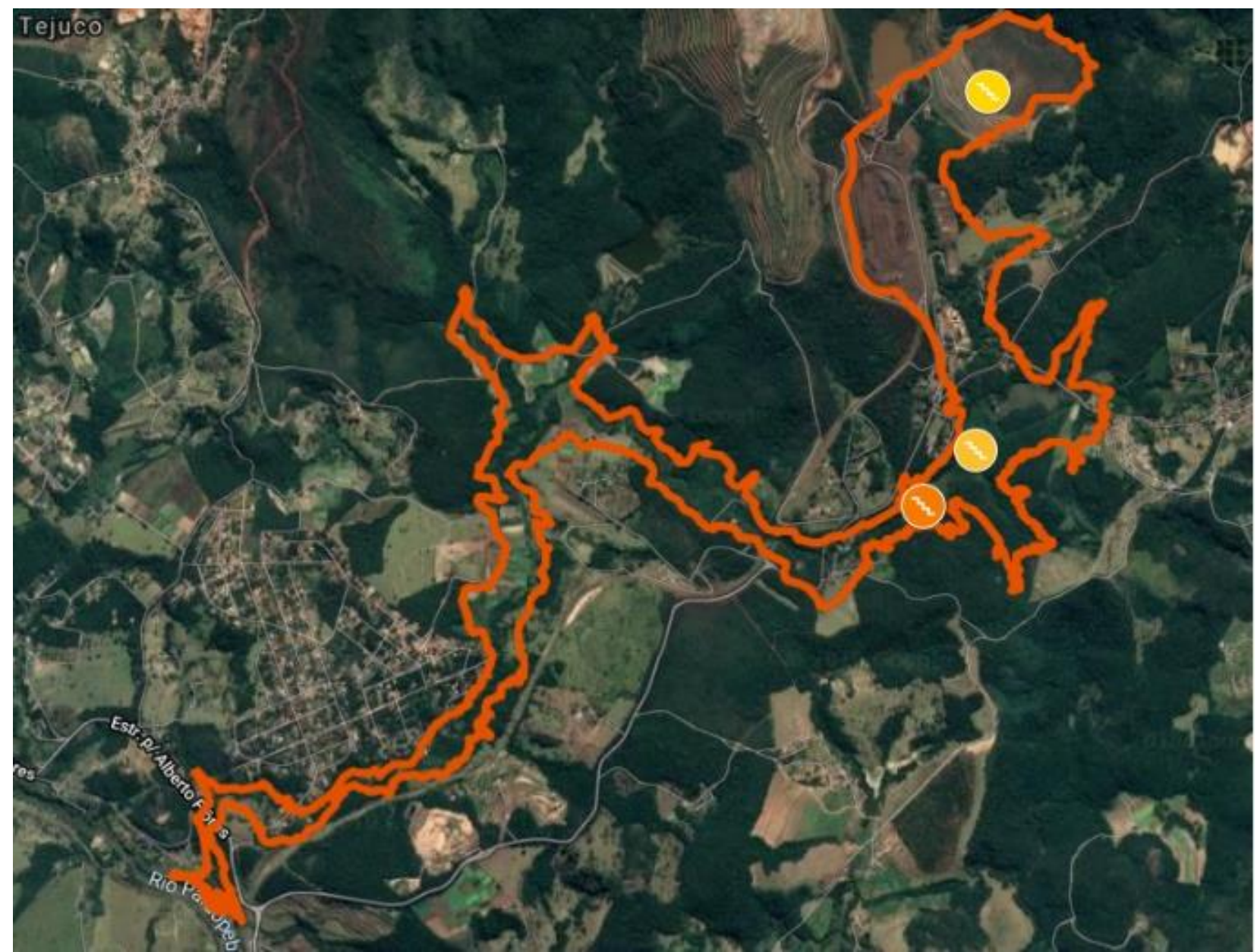

Figure 1. Region affected by the reject in Brumadinho-MG. Font: General Procuratorate Office of the State of Minas Gerais (2019).

\begin{tabular}{|r|r|r|r|r|r|r|r|r|r|}
\hline 119 & 120 & 121 & 122 & 123 & 124 & 125 & 126 & 127 & 128 \\
\hline 151 & 152 & 153 & 154 & 155 & 156 & 157 & 158 & 159 & 160 \\
\hline 183 & 184 & 185 & 186 & 187 & 188 & 189 & 190 & 191 & 192 \\
\hline 215 & 216 & 217 & 218 & 219 & 220 & 221 & 222 & 223 & 224 \\
\hline 247 & 248 & 249 & 250 & 251 & 252 & 253 & 254 & 255 & 256 \\
\hline 279 & 280 & 281 & 282 & 283 & 284 & 285 & 286 & 287 & 288 \\
\hline 311 & 312 & 313 & 314 & 315 & 316 & 317 & 318 & 319 & 320 \\
\hline 343 & 344 & 345 & 346 & 347 & 348 & 349 & 350 & 351 & 352 \\
\hline
\end{tabular}

Figure 2. Sub-regions for the construction of the vector field. Font: Pinheiro et al. (2021). 


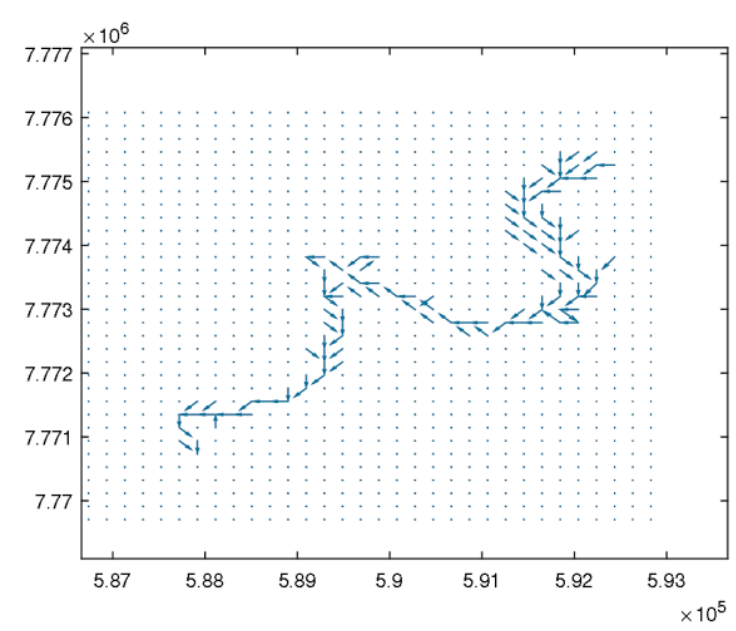

Figure 3. Artificial vector field. Font: Pinheiro et al. (2021).

The geographic coordinates were transformed into UTM (Universal Transverse Mercator) coordinates, which enable a horizontal axis and a vertical axis. Thereby, all calculations were performed using functions of two variables in the domain.

\section{ii. Getting the drag force}

According to Muson et al. (2004), the drag force is calculated point-by-point through Equation 1:

$F_{D}=0,5 \cdot C_{D} \cdot \rho \cdot U^{2} \cdot A$,

where $F_{D}=$ drag force, $\rho=$ specific mass or density of the fluid, $U=$ velocity on the route, and $A=$ cross-sectional area of the body towards the flow direction. We considered $A=1$. The drag coefficient, $C_{D}$, is obtained from the number of Reynolds via tabulated values in Muson et al. (2004). It was used $C_{D}=1.1$. The density we chose $\rho=1500 \mathrm{~kg} \cdot \mathrm{m}^{-3}$ (Alvarado et al. (2006)). Alvarado et al. (2006). The velocity $U$ is obtained doing $U(t)=10-e^{\frac{t}{25500}}$. This function for velocity was modeled following the literature (Alvarado et al., 2006). The average velocity of the tailings when the dam break happens is approximately $9 \mathrm{~m} . \mathrm{s}-1$, being that along the trajectory, this is the trajectory velocity decreases. After a certain interval (approximately 14 hours), the velocity goes up to $2 \mathrm{~m} \cdot \mathrm{s}^{-1}$.

\section{iii. The victim's velocity and position}

Finally, using numerical integration, using cumtrapz Matlab ${ }^{\circledR}$ function, the victim's velocity and position are obtained. Although there are discussions about the reject being considered or not Newtonian, in the approach presented here, we consider it to be Newtonian.
Algorithm 1 represents the main code of the physicomathematical algorithm, which returns an estimate of the victim's position over time.

Remark 1. Specific functions have been created that run in conjunction with the main program. These functions transform the region's coordinates into UTM coordinates, determine the region $r_{i}$ where the victim is located, generate the artificial vector field, provide the fluid's $U$ velocity from that field and calculate the drag force from Equation 1.

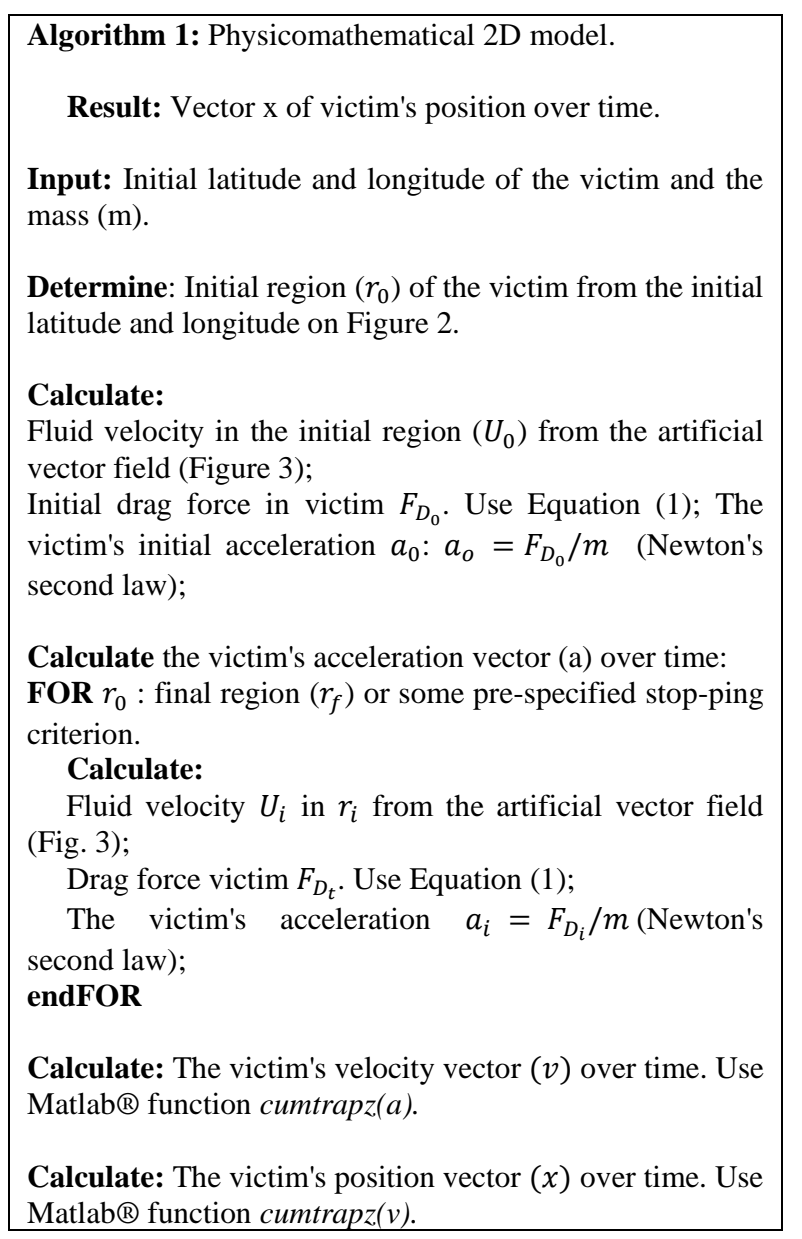

Remark 2. It was emphasized that the algorithm is adaptable to new information to make the computational model as close to real as was wished. One of these adaptations can be observed through the term "some pre-specified stopping criterion" means that we can define obstacles coming from the relief, vegetation, or diverse constructions as stopping criteria.

\section{iv. Future versions}

In future versions of the model, an artificial vector field with a larger number of data (Figure 4) is also constructed a vector field with an algorithm based on the descending gradient (Figure 5), via information from the digital terrain model (DTM) (Figure 6). Therefore, through the two new vector 
fields, one wants to get a vector field closer to the real one and insert it into the algorithm.

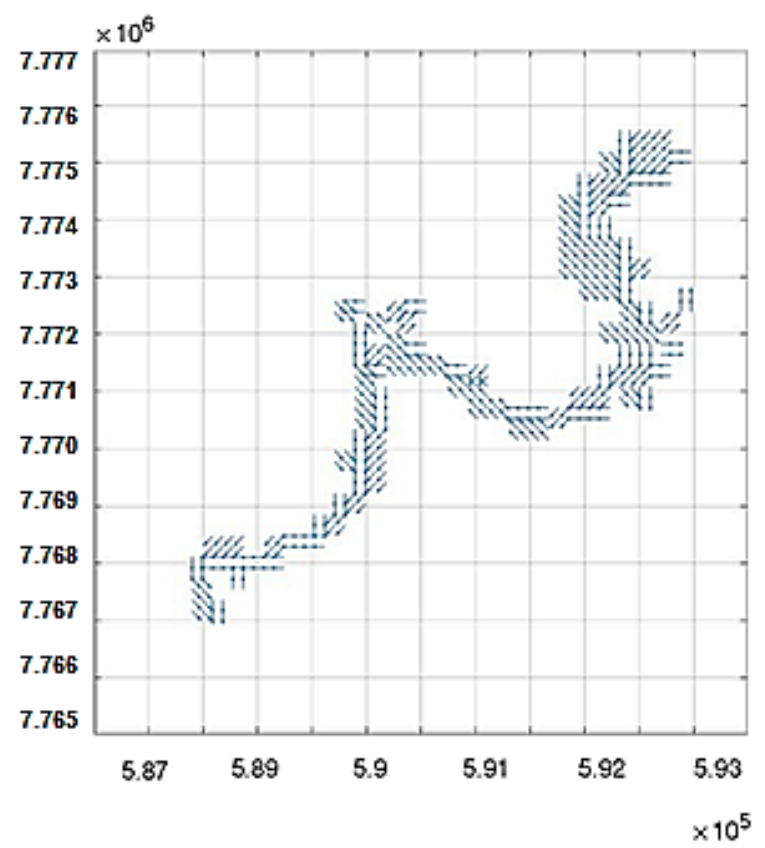

Figure 4. New artificial vector field. Font: Pinheiro et al. (2021).

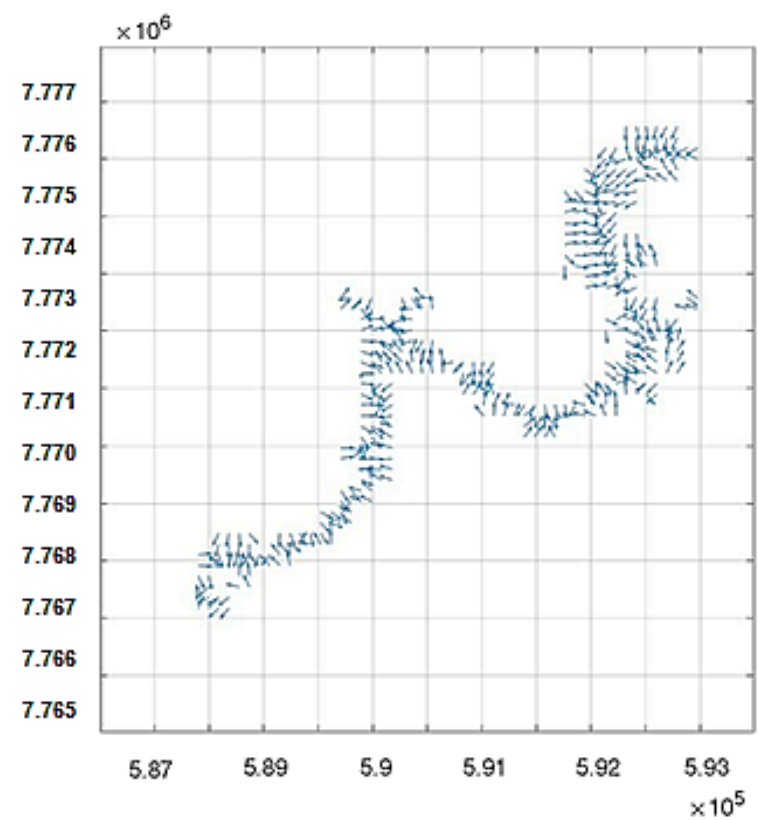

Figure 5. Vector Field via DTM. Font: Pinheiro et al. (2021).

\section{v. Results of the Physicomathematical Model}

The adjustment of the algorithm was performed using displacement of the ID63 victim. Table 1 shows that the trajectory of the victim, provided by the trajectory modeled by the algorithm, corresponds to the actual position where the victim was located. Stopping criteria can be inserted in the model to estimate final positions; such criteria can model topographic obstacles, vegetation, and constructions.

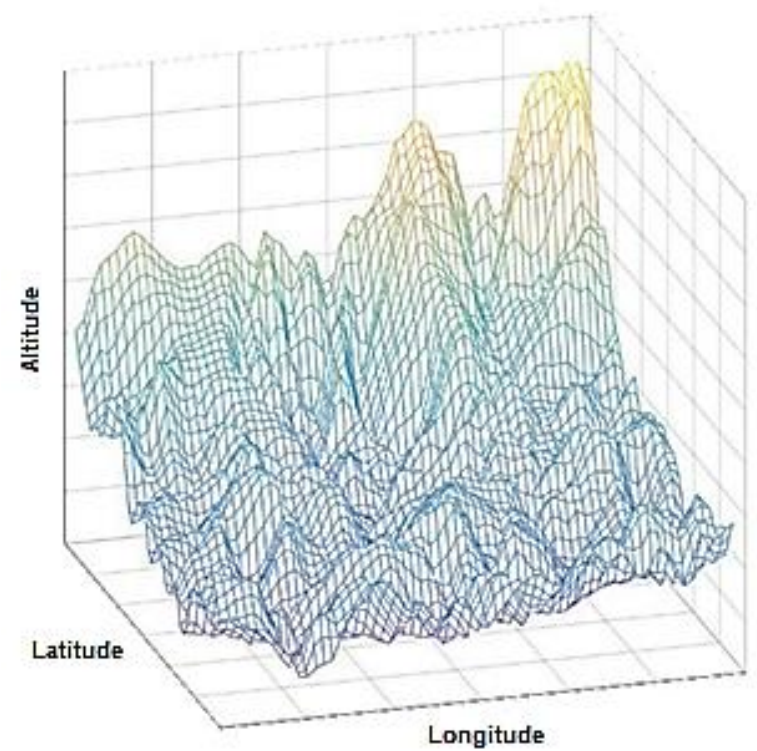

Figure 6. Digital terrain model (DTM) of Brumadinho-MG. Font: Pinheiro et al. (2021).

Table 1. Model adjustment. Font: Pinheiro et al. (2021).

\begin{tabular}{|c|l|l|l|}
\hline \multicolumn{3}{|l|}{ Victim } & \multicolumn{3}{|c|}{ ID63 } \\
\hline \multicolumn{2}{|l|}{ Initial position } & $-\mathbf{2 0 . 1 3 1 6 3}$ & $-\mathbf{4 4 . 1 2 0 9 3}$ \\
\hline \multicolumn{2}{|l|}{ Final position } & $\mathbf{- 2 0 . 1 3 9 4 2}$ & $-\mathbf{4 4 . 1 3 4 4 2}$ \\
\hline & $\mathbf{s e c})$ & Lat. & Long. \\
\hline 1 & 575.40790 & -20.13160 & -44.12090 \\
\hline 2 & 1150.8000 & -20.13350 & -44.11840 \\
\hline 3 & 1813.1000 & -20.13540 & -44.11640 \\
\hline 4 & 2369.4000 & -20.13740 & -44.11840 \\
\hline 5 & 3395.20000 & -20.13930 & -44.12030 \\
\hline 6 & 4299.40000 & -20.14120 & -44.11840 \\
\hline 7 & 5288.90000 & -20.14120 & -44.12040 \\
\hline 8 & 6275.40000 & -20.13940 & -44.12240 \\
\hline 9 & 7183.00000 & -20.14130 & -44.12440 \\
\hline 10 & 8181.8000 & -20.14130 & -44.12640 \\
\hline 11 & 9196.0000 & -20.14320 & -44.12840 \\
\hline 12 & 10310.000 & -20.14130 & -44.13040 \\
\hline 13 & 11372.000 & -20.14130 & -44.13240 \\
\hline 14 & 12465.0000 & -20.13940 & -44.13440 \\
\hline
\end{tabular}

Table 2. Model validation. Font: Pinheiro et al. (2021).

\begin{tabular}{|c|c|c|c|}
\hline Victi & \multicolumn{3}{|c|}{ ID29 } \\
\hline \multicolumn{2}{|c|}{ Initial position } & -20.13150 & -44.11971 \\
\hline \multicolumn{2}{|c|}{ Final position } & -20.13908 & -44.13422 \\
\hline & $\mathrm{t}(\mathrm{sec})$ & LAT. & LONG. \\
\hline 1 & 575.40790 & -20.13150 & -44.11971 \\
\hline 2 & 1150.8000 & -20.13350 & -44.11840 \\
\hline 3 & 1813.1000 & -20.13540 & -44.11640 \\
\hline 4 & 2569.4000 & -20.13740 & -44.11840 \\
\hline 5 & 3395.2000 & -20.13930 & -44.12030 \\
\hline 6 & 4299.4000 & -20.14120 & -44.11840 \\
\hline 7 & 5288.9000 & -20.14120 & -44.12040 \\
\hline
\end{tabular}




\begin{tabular}{|c|c|c|c|}
\hline 8 & 6275.4000 & -20.13940 & -44.12240 \\
\hline 9 & 7183.0000 & -20.14130 & -44.12440 \\
\hline 10 & 8181.8000 & -20.14130 & -44.12640 \\
\hline 11 & 9196.0000 & -20.14320 & -44.12840 \\
\hline 12 & 10310.0000 & -20.14130 & -44.13040 \\
\hline 13 & 11372.0000 & -20.14130 & -44.13240 \\
\hline 14 & 12465.0000 & -20.13940 & -44.13440 \\
\hline Victim & \multicolumn{3}{|c|}{ ID66 } \\
\hline \multicolumn{2}{|c|}{ Initial position } & -20.13016 & -44.1216 \\
\hline \multicolumn{2}{|c|}{ Final position } & -20.13728 & -44.11986 \\
\hline & $\mathrm{t}(\mathrm{sec})$ & LAT. & LONG. \\
\hline 1 & 499.42870 & -20.1302 & -44.1216 \\
\hline 2 & 998.8573 & -20.1316 & -44.1203 \\
\hline 3 & 1574.3000 & -20.1336 & -44.1183 \\
\hline 4 & 2236.60 & -20.1355 & -44.1164 \\
\hline 5 & 2992.9000 & -20.1375 & -44.1183 \\
\hline
\end{tabular}

After the adjustment of the model, some tests were performed with other victims, according to Table 2. One can notice an error between the actual final value and the model's final trajectory value. This error may be reduced using the future version of the model, as mentioned in the previous section. Table 3 shows the module of errors.

Table 3. Error between the actual final value and the model's final trajectory value for victims ID29 and ID66. Font: Pinheiro et al. (2021).

\begin{tabular}{|l|c|c|}
\cline { 2 - 3 } \multicolumn{1}{c|}{} & LAT. & LONG. \\
\hline Victim ID29 & 0.00032 & 0.00018 \\
\hline Victim ID66 & 0.00022 & 0.00156 \\
\hline
\end{tabular}

Lastly, and a result that was provided to the search teams, the algorithm provided, as shown in Table 4, possible trajectories of victims who were in the dining hall at the time of the catastrophe.

\section{Hybrid Model 1 based on Interpolation Techniques and the Physicomathematical Model}

The possibility of building hybrid models was visualized using the model previously presented. A hybrid model based on regression techniques was constructed from this idea, which provided some partial results. This model works together with the physicomathematical model 2D and is intended to improve victims' final position.

Two simple regression statistical models were obtained based on linear interpolation approximation and cubic splines, taking primary reference to Burden et al. (2015). These interpolations are an adjustment based on a larger hybrid model, which is used to estimate the locations of the bodies, which involves both an approach based on the physicomathematical model, such as linear interpolation and cubic splines. The models were tested, and their results are presented below.

Table 4. Position estimates for victims who were in the dining hall. Font: Pinheiro et al. (2021).

\begin{tabular}{|c|c|c|c|}
\hline \multicolumn{4}{|c|}{ Dining hall } \\
\hline \multicolumn{2}{|c|}{ Initial position } & -20.13213 & -44.12142 \\
\hline & t (sec) & Lat. & Long. \\
\hline 1 & 575.40790 & -20.1321 & -44.1214 \\
\hline 2 & 1150.80000 & -20.1335 & -44.1184 \\
\hline 3 & 1813.10000 & -20.1353 & -44.1165 \\
\hline 4 & 2569.40000 & -20.1372 & -44.1184 \\
\hline 5 & 3395.20000 & -20.1391 & -44.1203 \\
\hline 6 & 4299.40000 & -20.1409 & -44.1184 \\
\hline 7 & 5288.90000 & -20.1409 & -44.1203 \\
\hline 8 & 6275.40000 & -20.1391 & -44.1222 \\
\hline 9 & 7183.00000 & -20.141 & -44.124 \\
\hline 10 & 8181.80000 & -20.141 & -44.1259 \\
\hline 11 & 9196.00000 & -20.1428 & -44.1278 \\
\hline 12 & 10310.00000 & -20.141 & -44.1297 \\
\hline 13 & 11372.00000 & -20.141 & -44.1316 \\
\hline 14 & 12465.00000 & -20.1391 & -44.1334 \\
\hline 15 & 13523.00000 & -20.1373 & -44.1353 \\
\hline 16 & 14558.00000 & -20.1373 & -44.1372 \\
\hline 17 & 15643.00000 & -20.1354 & -44.1391 \\
\hline 18 & 16722.00000 & -20.1354 & -44.141 \\
\hline 19 & 17860.00000 & -20.1336 & -44.1429 \\
\hline 20 & 19010.00000 & -20.1317 & -44.1448 \\
\hline 21 & 20182.00000 & -20.1317 & -44.1466 \\
\hline 22 & 21424.00000 & -20.1336 & -44.1448 \\
\hline 23 & 22639.00000 & -20.1355 & -44.1447 \\
\hline 24 & 23900.00000 & -20.1373 & -44.1447 \\
\hline 25 & 25211.00000 & -20.1392 & -44.1428 \\
\hline 26 & 26518.00000 & -20.1411 & -44.1428 \\
\hline 27 & 27883.00000 & -20.143 & -44.1428 \\
\hline 28 & 29308.00000 & -20.1448 & -44.1447 \\
\hline 29 & 30847.00000 & -20.1467 & -44.1447 \\
\hline 30 & 32448.00000 & -20.1486 & -44.1447 \\
\hline 31 & 34113.00000 & -20.1505 & -44.1465 \\
\hline 32 & 35892.00000 & -20.1524 & -44.1484 \\
\hline 33 & 37784.00000 & -20.1524 & -44.1503 \\
\hline 34 & 39725.00000 & -20.1524 & -44.1522 \\
\hline 35 & 41719.00000 & -20.1542 & -44.154 \\
\hline 36 & 43826.00000 & -20.1543 & -44.1559 \\
\hline 37 & 45987.00000 & -20.1543 & -44.1578 \\
\hline 38 & 48203.00000 & -20.1543 & -44.1597 \\
\hline 39 & 50475.00000 & -20.1562 & -44.1597 \\
\hline 40 & 52804.0000 & -20.158 & -44.1578 \\
\hline
\end{tabular}

\section{i. Hybrid 1: Results}

Figure 7 shows a trend type or probability of finding the bodies using linear interpolation. The locations pointed by orange color were generated 
using the blue color samples estimated by physicomathematical model.

Figure 8 shows the method via interpolation by cubic splines, where the blue line represents the original raw data from the physicomathematical model and the orange line to the interpolated data.

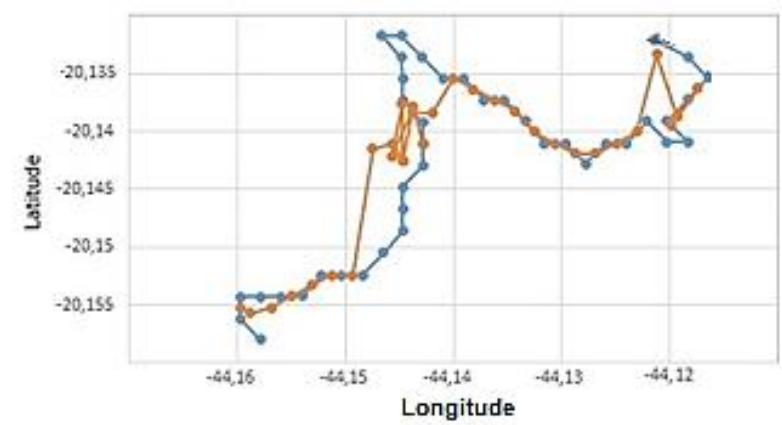

Figure 7. Position estimates for victims who were in the dining hall via linear interpolation. Font: Pinheiro et al. (2021).

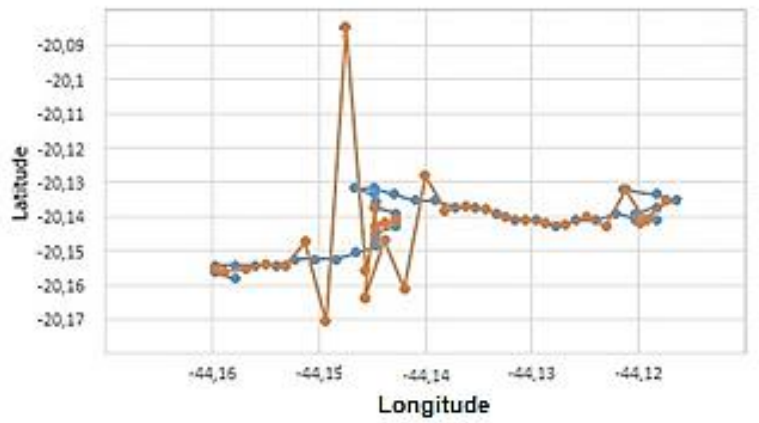

Figure 8. Position estimates for victims who were in the dining hall via cubic splines. Font: Pinheiro et al. (2021).

\section{Support Vector Regression (SVR)}

SVR is a type of statistically inspired supervised machine learning process. A critical study by Vapnik in 1964 brought the first ideas about the field of SVM, where it was approached the maximum margin hyperplane algorithm giving rise to the linear classifier, but only later in 1992 using kernel models that Boser et al. (1992) developed the famous study "Training Algorithm for Optimal Margin Classifiers", where the supervised learning algorithm was developed, a nonlinear classifier known as the Support Vector Machine.

Here, a supervised learning algorithm was developed: a nonlinear classifier known as the support vector regression. The method uses a parameter $v$ to control the number of support vectors. However, unlike $v$-SVC, where $C$ is replaced by $v$, here $v$ replaces the parameter $\epsilon$ of $\epsilon$ $\mathrm{SVR}$. The primal form is:

$$
\begin{aligned}
& \min _{\omega, b, \xi, \xi^{*}, \epsilon} \frac{1}{2} \omega^{T} \omega+C\left(v \epsilon+\frac{1}{l} \sum_{i=1}^{l}\left(\xi_{i}+\xi_{i}^{*}\right)\right. \\
& \left(\omega^{T} \phi\left(x_{i}\right)+b\right)-z_{i} \leq \epsilon+\xi_{i}, \\
& z_{i}-\left(\omega^{T} \phi\left(x_{i}\right)+b\right) \leq \epsilon+\xi_{i}^{*}, \\
& \xi_{i}, \xi_{i}^{*} \geq 0, i=1, \ldots, l, \epsilon \geq 0,
\end{aligned}
$$

where $\phi\left(x_{i}\right)=$ function that can map data $x$ from low dimension to high dimension feature space, $w$ = weight vector, $b=$ numeric value that can be up or down, obtained via Karush-Kuhn-Tucker conditions (Burges, 1998), $\epsilon$ is the regularization parameter, $\xi$ and $\xi^{*}=$ relaxation factors. The dual form is:

$$
\begin{aligned}
& \min _{\alpha, \alpha^{*}} \frac{1}{2}\left(\alpha-\alpha^{*}\right)^{T} Q\left(\alpha-\alpha^{*}\right)+z^{T}\left(\alpha-\alpha^{*}\right) \\
& \epsilon^{T}\left(\alpha-\alpha^{*}\right)=0, \epsilon^{T}\left(\alpha-\alpha^{*}\right) \leq C v, \\
& 0 \leq \alpha, \alpha_{i}^{*} \leq \frac{C}{l}, i=1, \ldots, l .
\end{aligned}
$$

Similarly, the inequality $\epsilon\left(\alpha-\alpha^{*}\right) \leq C v$ can be replaced by an equality, where $\alpha$ and $\alpha^{*}$ are Lagrange multipliers $C \leftarrow \frac{C}{l}$, so the dual problem solved is:

$$
\begin{aligned}
& \min _{\alpha, \alpha^{*}} \frac{1}{2}\left(\alpha-\alpha^{*}\right)^{T} Q\left(\alpha-\alpha^{*}\right)+z^{T}\left(\alpha-\alpha^{*}\right) \\
& \epsilon^{T}\left(\alpha-\alpha^{*}\right)=0, \epsilon^{T}\left(\alpha-\alpha^{*}\right) \leq C l v, \\
& 0 \leq \alpha, \alpha_{i}^{*} \leq C, i=1, \ldots, l .
\end{aligned}
$$

Then, the decision function is:

$f(x)=\sum_{i=1}^{l}\left(-\alpha+\alpha_{i}^{*}\right) K\left(x_{i}, x\right)+b$,

the same as that of $\epsilon$-SVR, where $K$ is Kernel function.

Hybrid 2: Physicomathematical model with support vector regression

After entering the data originated from georeferencing of the region, the location and prediction are given after the physicomathematical algorithm, and then for optimizing the data, the SVR is used. By being a nonlinear problem, a kernel function is implemented, which will optimize the data. The final output is the approximate location of the victims. Therefore, the data refinement is done by optimizing the hyperplane using RBF. 
The organization chart in Figure 9 shows how the algorithm works. Firstly (1), the method consists of converting geographic coordinates of the region to UTM coordinates, then the coordinates are transferred to a text file and inserted in the Excel spreadsheet. Next (2), a pointto-point plot via vector calculus is made to create the surface of the vector field of tailings flow. The image is generated, generating information of velocity and flow (see Figure 3). In this case, there is an image of the Brumadinho region within Minas Gerais's map, which was drawn manually in a graphical tool software. After this entry point, topological data are inserted into the algorithm (3), then it goes through the computational fluid dynamics (CFD) analysis process that links to the physicomathematical model. After processing the model data, the prediction (4) and the location are provided (5). Finally, to optimize the generated location data SVR is used. Because this problem is treated non-linearly, together with the SVR is implemented a radial kernel function (6). After the data is processed (7) and the output is the approximate location of the victims optimized (8).

The computational code of the method SVR is summarized by Algorithm 2, which results in the victims' optimized position.

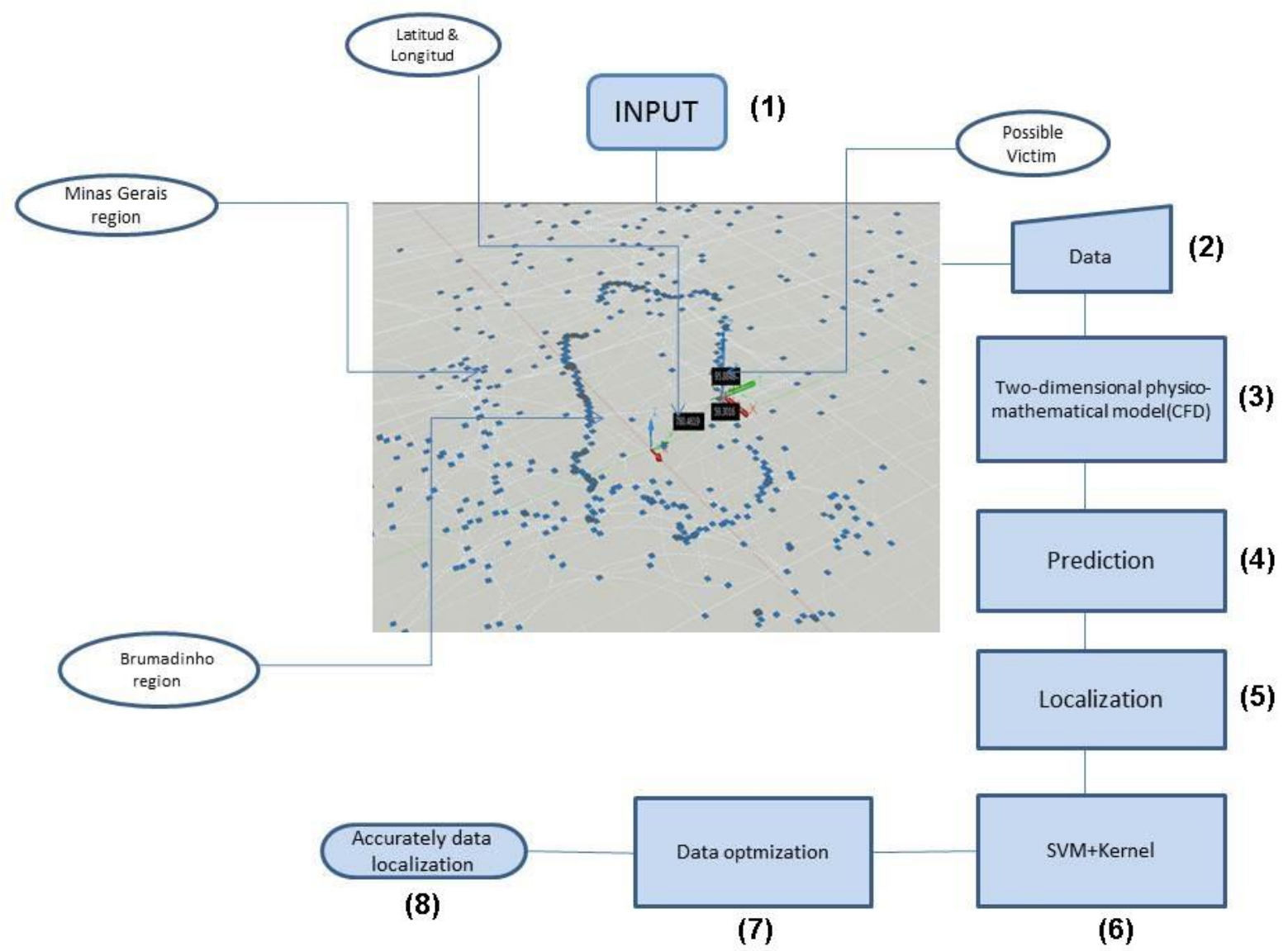

Figure 9. Hybrid computational model - Physicomathematical Model with Support Vector Regression. Font: Pinheiro et al. (2021).

\section{ii. Hybrid 2: results}

Figure 10 shows a SVR using a linear kernel function applied to the output data estimated by the physicomathematical model. The red curve representing the estimated adjustment of the linear regression on the physicomathematical model data does not have good accuracy since it presents a substantial deviation.

Figure 11 shows an SVR applied to the output data estimated by the physicomathematical model algorithm using a sigmoid kernel function. In this case, there is also a lack of accuracy in the regression, characterized by a considerable deviation from the red curve when adjusted over the output data generated by the physicomathematical model.

Figure 12 shows an SVR using a polynomial kernel function of order 3 applied to the output data estimated by the physicomathematical model. In this case, again, there is a significant lack of accuracy in the regressive process. 

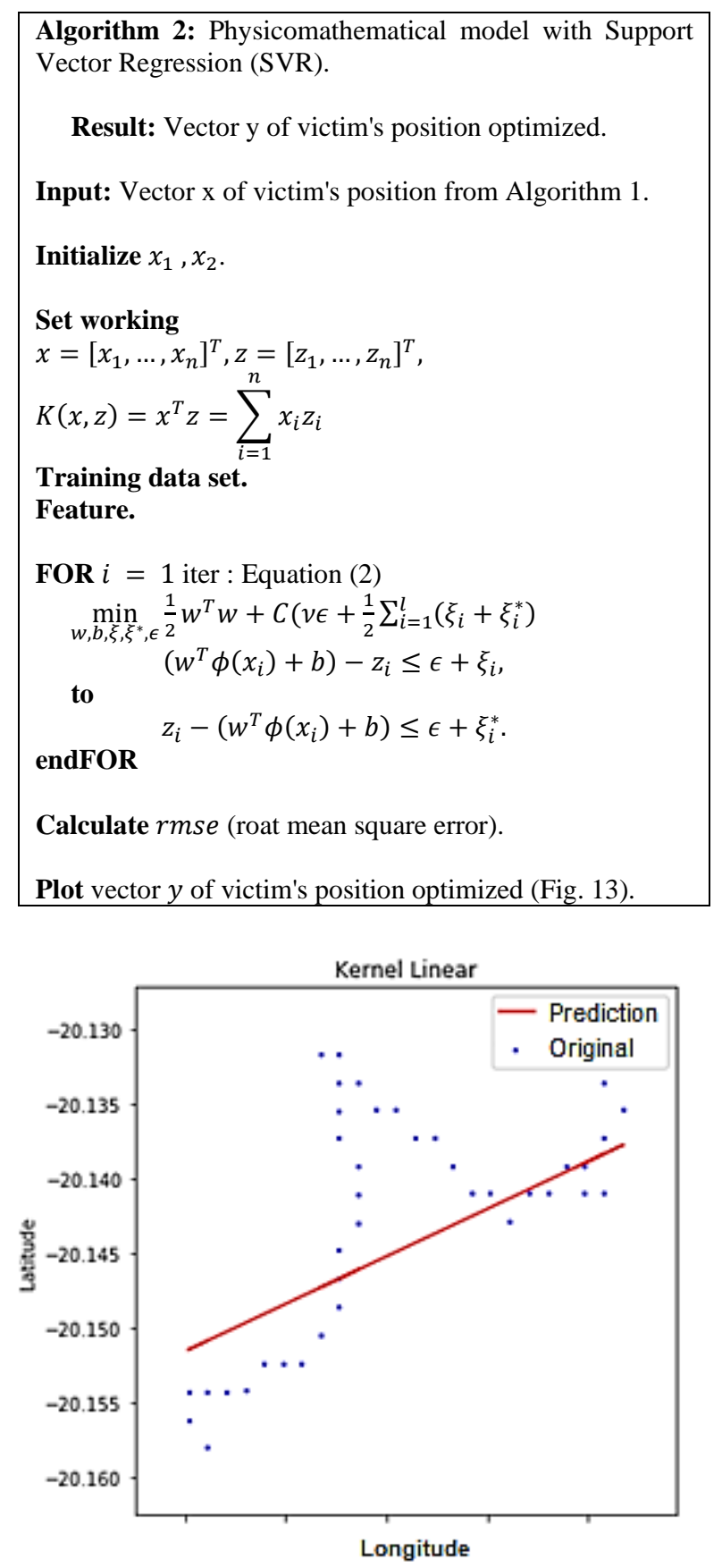

Figure 10. SVR using a linear kernel function. Font: Pinheiro et al. (2021).

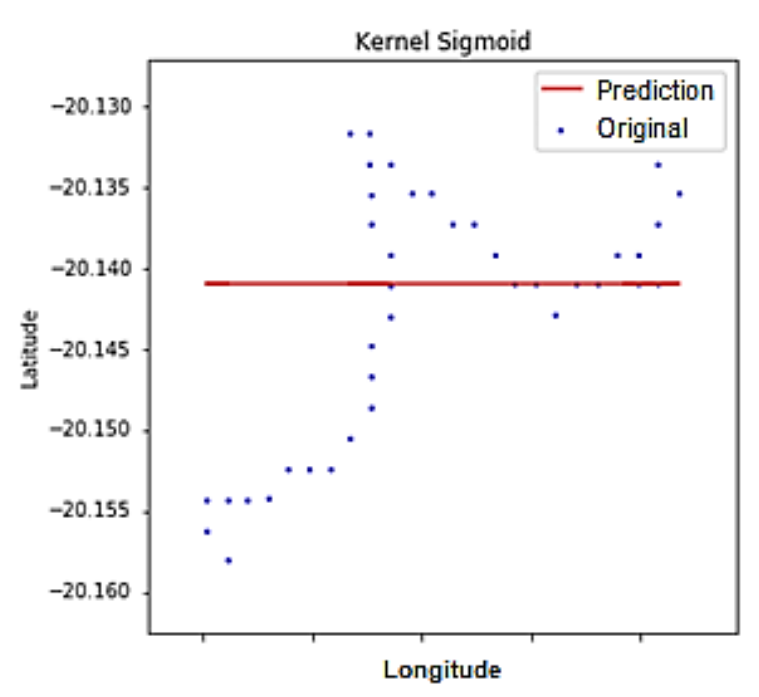

Figure 11. SVR using a sigmoid kernel function. Font: Pinheiro et al. (2021).

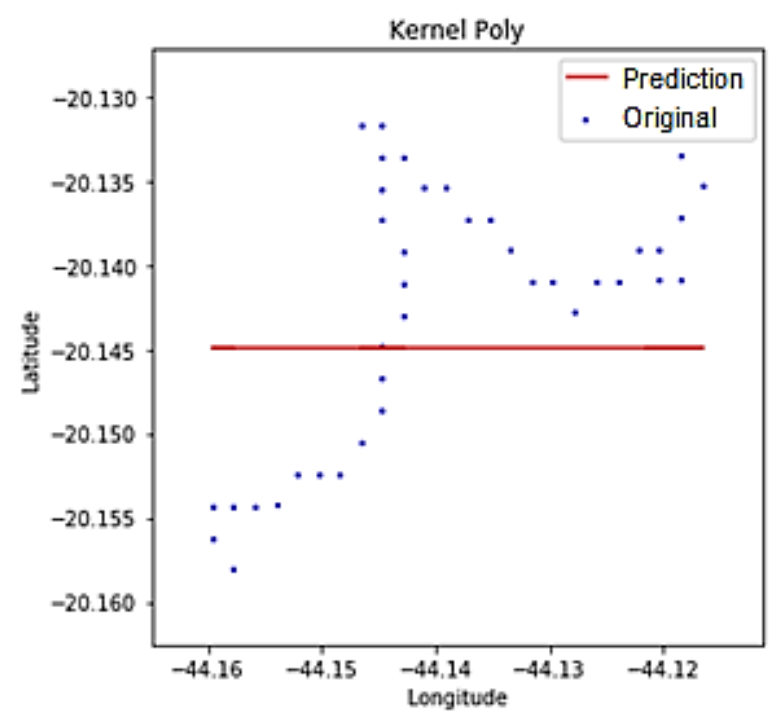

Figure 12. SVR using a polynomial kernel function. Font: Pinheiro et al. (2021).

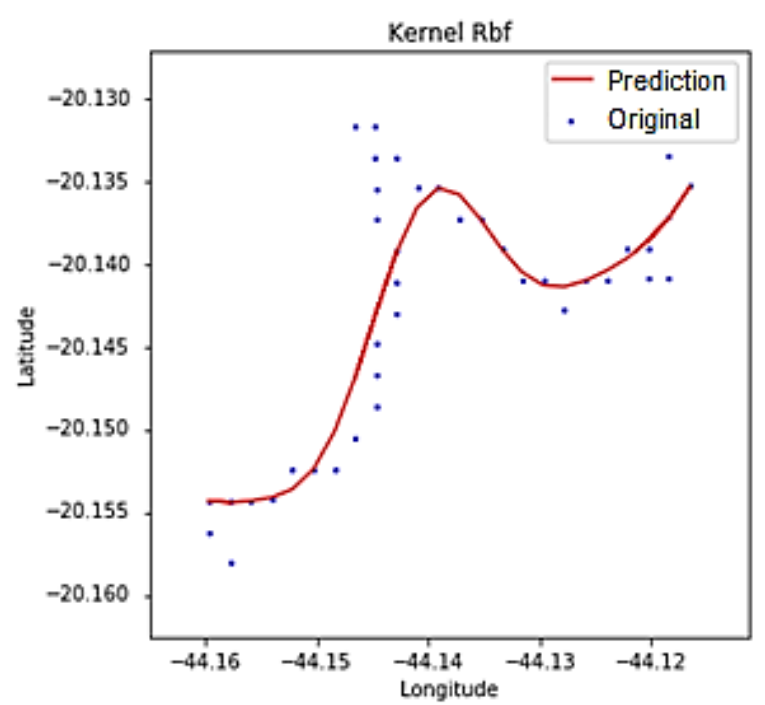

Figure 13. SVR using kernel RBF. Font: Pinheiro et al. (2021). 
Finally, Figure 13 shows an SVR using a kernel function based on the RBF applied to the physicomathematical model output data. In this case, the regression reasonably adjusts the regressive curve on the physicomathematical model output data. Therefore, this method produces a useful regularization over physicomathematical model data.

\section{Conclusion}

A physicomathematical model that simulates the tailings flow and estimates the location of victims of the Brumadinho tragedy was developed. This model proved to be efficient, as indicated by the error in Table 3 . In addition, hybrid models were developed using regression and SVRRBF techniques to improve the estimates of the physics-mathematical model.

In future works, it is intended to improve the hybrid model making improvements in the physicomathematical model. These improvements will be based on ordinary differential equations and obtaining a vector field closer to the real. The new vector field can be obtained from the resultant between artificial vector fields that use more data and vector fields generated from the DTM via techniques using the downward gradient algorithm. Also, we intend to extend the 2D methodology to 3D. In addition to physicomathematical model with SVR, we propose to use optimization via deep learning algorithms in the future.

\section{Acknowledgements}

Authors thank Prof. Dra. Vânia de Oliveira Neves (Universidade Federal Fluminense - UFF) for the initiative and coordination of the Group Science for Brumadinho, as well as all the researchers of this group; the GPOSMG for the cordiality and supply of information at the time of the tragedy that made the development of the physicomathematical algorithm; the heroic men of the fire department and civil defense who worked very hard in the Brumadinho's tragedy.

Authors declare solidarity and sincere feelings to the families of the victims of Brumadinho's tragedy.

\section{References}

Alvarado, L. A. S. 2006. Two-dimensional simulation of debris runs using the Discrete Element Method (in Portuguese). Master's thesis. PUC-Rio. Rio de Janeiro, Brasil. 154p.

Weter, D.; Galvão, D. 2019. Brumadinho Dam has a volume of 12.7 million $\mathrm{m}^{3}$ of mining rejects. (in Portuguese). Cotidiano-Uol Notícias. Available at: https://noticias.uol.com.br/ultimas- noticias/agencia-

estado/2019/01/25/barragem-em-

brumadinho-tem-volume-de-1-milhao-de-mde-rejeito-de-mineracao.htm. Access on: 31 August 2021.

Boser, B. E.; Guyon I. M.; Vapnik, V. N. 1992. A Training Algorithm for Optimal Margin Classifiers. In: D. Haussler (Ed.), COLT '92: Proceedings of the fifth annual workshop on Computational. New York: ACM Press. pp. 144-152.

Burden, R. L.; Faires, J. D.; Burden., A. M. 2015. Numerical Analysis. Cengage Learning. 912p.

Burges, C. J. 1998. A Tutorial on Support Vector Machines for Pattern Recognition. Data Mining and Knowledge Discovery, 2, 121167.

Daneshvar, P.; Zsaki, A. M. 2018. Simulation of tailings flow resulting from a dam breach using smoothed particle hydrodynamics. Environmental and Engineering Geoscience, 24, (3), 263-279.

Gomes., H. S. 2020. From mud to patent: scientists made Brumadinho's tragedy turn into innovation. (in Portuguese). Tilt-Uol Notícias. Available at: https://www.uol.com.br/tilt/noticias/redacao/ 2020/02/12/morte-na-lama-como-cientistasinovaram-apos-tragedia-de-brumadinho.htm. Access on: 29 September 2020.

Guzman, S. M.; Paz, J. O.; Tagert, M. L. M. et al. 2019. Evaluation of Seasonally Classified Inputs for the Prediction of Daily Groundwater Levels: NARX Networks Vs Support Vector Machines. Environ Model Assess, 24, 223-234.

Li, X.; Luo, A.; Li, J. et al. 2019. Air Pollutant Concentration Forecast Based on Support Vector Regression and Quantum-Behaved Particle Swarm Optimization. Environ Model Assess, 24, 205-222.

Luo, C.; Xu, K.; Zhao, Y. 2017. A TVD discretization method for shallow water equations: Numerical simulations of tailing dam break. International Journal of Modeling, Simulation, and Scientific Computing, 08, (03), 1850001.

Marcolino, D. A.; Medina, A.; Rafael, C. M.; Amner, R. 2018. Periodic Steady State Assessment of Microgrids with Photovoltaic Generation Using Limit Cycle Extrapolation and Cubic Splines. Energies, 11, (8), 2096.

Moazenzadeh, R.; Mohammadi, B.; Shamshirband, S.; Chau, K. 2018. Coupling a firefly algorithm with support vector regression to predict evaporation in northern Iran. 
Engineering Applications of Computational Fluid Mechanics, 12, (1), 584-597.

Muson, B. R.; Young, D. F.; Okiishi, T. H. 2004. Fundamentos da Mecânica dos Fluidos. Edgar Blüsher. 584p.

Piovezan., S. 2019. How network of scientists uses data to try to find bodies in Brumadinho. (in Portuguese). Uol Notícias. Available at: https://www.uol.com.br/tilt/noticias/redacao/ 2019/03/08/cientistas-criam-rede-paraajudar-vitimas-de-brumadinho-e-evitartragedias.htm. Access on: 29 September 2020.

Qasem, S. N.; Samadianfard, S.; Kheshtgar, S. et al. 2019. Modeling monthly pan evaporation using wavelet support vector regression and wavelet artificial neural networks in arid and humid climates. Engineering Applications of Computational Fluid Mechanics, 13, (1), 177187.

Rehamnia, I.; Benlaoukli, B.; Heddam, S. 2020. Modeling of Seepage Flow Through Concrete Face Rockfill and Embankmen Dams Using Three Heuristic Artificial Intelligence Approaches: A Comparative Study. Environ. Process, 7, 367-381.

Santamaría-Bonfil, G.; Reyes-Ballesteros, A.; Gershenson., C. 2016. Wind speed forecasting for wind farms: A method based on support vector regression. Renewable Energy, 85, 790-809.

Seyedashraf, O.; Mehrabi, M.; Akhtari, A. A. 2018. Novel approach for dam break flow modeling using computational intelligence. Journal of Hydrology, Vol. 559.

Tabari, M. M. R.; Sanayei, H. R. Z. 2019. Prediction of the intermediate block displacement of the dam crest using artificial neural network and support vector regression models. Soft Comput, 23, 9629-9645.

Vacondio, R.; Palù, A. D.; Mignosa, P. 2014 GPUenhanced Finite Volume Shallow Water solver for fast flood simulations. Environmental Modelling \& Software, 57, 60-75.

Zhang, M., Xu, Y.; Qiao, H. 2018. Numerical Study of Hydrodynamic and Solute Transport with Discontinuous Flows in Coastal Water. Environ Model Assess, 23, 353-367.

Zhou, J.; Causon, D.; Mingham, C.; Ingram., D. 2004. Numerical Prediction of Dam Break Flows in General Geometries with Complex Bed Topography. Journal of Hydraulic Engireering, 130, (4), 332-340. 